\title{
Understanding the Spatially Variable Effects of Climate Change on Rice Yield for Three Ecotypes in Bangladesh, 1981-2010
}

\author{
Iffat Ara, ${ }^{1,2}$ Megan Lewis, ${ }^{1}$ and Bertram Ostendorf ${ }^{1}$ \\ ${ }^{1}$ School of Biological Sciences, The University of Adelaide, Adelaide, SA 5005, Australia \\ ${ }^{2}$ Department of Geography and Environment, Jahangirnagar University, Savar, Dhaka 1342, Bangladesh \\ Correspondence should be addressed to Iffat Ara; iffatara.ju@gmail.com
}

Received 16 March 2017; Revised 31 July 2017; Accepted 20 August 2017; Published 8 October 2017

Academic Editor: Albino Maggio

Copyright (c) 2017 Iffat Ara et al. This is an open access article distributed under the Creative Commons Attribution License, which permits unrestricted use, distribution, and reproduction in any medium, provided the original work is properly cited.

\begin{abstract}
Climate change will impact on rice food security in many parts of the world, including Bangladesh. Little attention has been given to understanding the impact of climate on rice yield for three main ecotypes (Aus, Aman, and Boro) in different areas of the country. The aim of this paper was to analyse the spatiotemporal dynamics of rice yield and climatic variables and the spatially variable climate effects on rice yield for these ecotypes in Bangladesh during 1981-2010 by employing linear mixed models and generalized linear models. The results demonstrated the substantial spatiotemporal variations of rice yield for all ecotypes across the country. Rice yield for ecotypes was more susceptible to temperature changes than rainfall effects. Modelling of a $1^{\circ} \mathrm{C}$ temperature increase in the country showed strong regional differences in rice yield for these ecotypes. The study concludes that future temperature changes are likely to change regional rice yield for all ecotypes and hence impact food security. The results have important consequences for food security by indicating the need for appropriate region-specific adaptation measures to reduce rice yield variability in the future. The results show the need to consider spatial differences for policy development to improve food security in Bangladesh.
\end{abstract}

\section{Introduction}

Rice is considered as a key food in daily life in many countries and rice production substantially influences global food security. Rice has become a primary concern for national food security in Bangladesh [1-3]. Climate change may influence rice food security in many parts of the world including Bangladesh [4, 5]. Bangladesh primarily produces three ecotypes of rice (Aus, Aman, and Boro) in three different climatic seasons. Changes in seasonal climatic conditions may have an impact on food security $[6,7]$ by affecting rice agriculture variability $[8,9]$ in different areas. Little is known about regional rice yield differences in Bangladesh for these ecotypes as a consequence of climate change.

Rice is fundamentally important for Bangladesh as it is the staple food for its 152 million people (population counted in the last population census, 2011) [10]. Bangladesh stands fourth in the ratings of per capita rice consumption in the world [11]. The average annual per capita rice consumption in Bangladesh is 160 kilograms [11], which is more than three times higher than the average global rice consumption rate
(50 kilograms per capita) [12]. Production of rice covers nearly $75 \%$ of the total cropland and over $80 \%$ of the total irrigated area in the country [13]. Rice contributes more than $60 \%$ of the total crop agriculture and accounts for $18 \%$ of the gross domestic product (GDP) in the country [14]. In addition, the lives and livelihoods of about 13 million farm households and approximately 50 per cent of the workforce, who are engaged in agriculture primarily, depend on rice production [10]. Rice production has increased substantially in Bangladesh since independence, which has positively influenced food security. However, the production of rice must continue to increase in order to improve national food security in the future [2]. Due to the significant impact of rice production on agricultural systems, livelihoods, and food security in Bangladesh, there is a critical need to understand the spatiotemporal variability of rice agriculture and the spatially variable effects of climate change on rice yield for different ecotypes. Although the scientific and policy recommendations have already covered crop agriculture changes due to climate change [15], there is still an urgent need to provide additional policy suggestions by understanding regional 
differences in rice production due to spatially variable climate change effects $[16,17]$. Region-specific adaptation measures can then be targeted appropriately for these ecotypes in different areas and so help in increasing farmers' abilities to cope with uncertain climate conditions for rice production in these areas in future.

Bangladesh's rice agriculture typically depends on climatic conditions, particularly temperature and rainfall. Rice grows intensively all over the country in three seasons: Aus season, March to August; Aman season, June to November; and Boro season, December to May [18]. There is a chance that the seasonal changes in temperature and rainfall in different areas may influence rice production for various ecotypes. However, the country has few regional adaptation measures yet in place to combat the effects of climate change on rice cultivation $[19,20]$. Earlier studies have quantified the impact of climate change on Bangladesh's rice agriculture for different ecotypes through the use of crop models [21-24] and empirical models $[16,17,24]$. The results of the Decision Support System for Agrotechnology Transfer (DSSAT) crop model showed a $35 \%$ decrease in the total rice yield in Bangladesh when there is an increase in temperature [21]. Mahmood et al. [25] indicated that $27 \%$ to $75 \%$ of Aman rice yield losses were due to the change of transplanting date for local climatic conditions in selected areas. However, crop model studies have placed little emphasis on geographic considerations and so further assessment is required to understand regional climate impacts on rice yield. Most of the empirical models explored the climate-rice yield relationship for three rice ecotypes from the historical records without considering any regional variability $[17,26]$. Sarker et al. [16] and Ruane et al. [24] indicated the considerable climate change impacts on rice yields for three ecotypes for broad climatic and agroecological zones, respectively. Another study focused on a particular district alone to understand the climate change impact on local rice yield [27]. Hence, the results of the existing studies are not adequate to understand the extent of the impact of climate change on rice yields in various districts of the country and therefore to devise necessary adaptation measures across Bangladesh.

Although there are well-established scientific concerns about the impact of climate change on rice yields and possible regional variabilities have also been studied on a broader scale $[16,24]$, district-level assessment is still needed for more specific detail. Some studies have analysed rice agricultural management on the basis of historical trends alone for different ecotypes [2, 28], but with no regional context. Recently, Ara et al. [1] investigated the spatiotemporal effects of climate change and other variables on the total rice yield in Bangladesh at the greater district level but did not consider such effects for various rice ecotypes grown in different seasons. In general, assessments on climate change impact at a regional scale are rare for Bangladesh's rice agriculture for the three ecotypes. This was acknowledged by Sarker et al. [26] and Amin et al. [17], who indicated the need for further district-level research on rice yield for these ecotypes in order to address region-specific adaptation measures in different seasons. The present study fills this research gap by focusing on spatially variable climate change effects on
Bangladesh's rice ecotypes during the 1981-2010 period at greater districts level. The specific objectives of the study are (1) to understand the spatiotemporal variations of rice yields for the three main ecotypes and the spatial variations of growing seasons climatic variability of these ecotypes across Bangladesh; (2) to evaluate the spatially variable impacts of climate on rice yield for three rice ecotypes; and (3) to assess regional rice yield changes due to a $1^{\circ} \mathrm{C}$ temperature increase in Bangladesh.

\section{Methods}

2.1. Rice Yield Data. Data for rice harvested area in a hectare (ha) for the three different ecotypes Aus, Aman, and Boro and total production of rice at greater districts level (tons) were obtained from the series of Agricultural Statistical Year Books of Bangladesh, published by the Bangladesh Bureau of Statistics (BBS) for the years 1981-2010. These data were then converted to an annual rice yield (tons/ha) for 23 greater districts in the country, dividing the rice production data by the harvested area for the respective ecotype.

2.2. Climate Data. Daily rainfall and maximum and minimum temperature data were sourced from the Bangladesh Meteorological Department [29] for 31 weather stations (Figure 1). Initially, we calculated the daily average temperature of each station from the maximum and minimum temperatures. In the next preparatory step, we calculated the average monthly temperature and monthly average rainfall for all stations. The kriging method was applied to interpolate the station-based climate data. The analysis was conducted using the ArcGIS Version 10.3 Geographic Information System. Finally, we derived 30-year (1981-2010) time series of seasonal average temperature and rainfall for all ecotype and all greater districts, respectively. Note that the climatic season calculation for Boro required consideration of two calendar years (e.g., December 1981 to May 1982 were considered for Boro yield of 1982).

2.3. Analysis. To assess the impact of climate change on the different ecotypes, we developed statistical models relating yield records from the government statistical yearbooks to the environmental conditions in the districts during the study period. We developed separate models for the three ecotypes (Aus, Aman, and Boro), respectively, and we used two model types to assess the impact of climate change at national and district levels. At the national level, we used linear mixed models (LMM) (1) with districts as a random effect in order to evaluate overall changes, yet acknowledging the spatial variability in the models:

$$
\begin{aligned}
Y_{i j}= & \beta_{0}+\beta_{1}\left(T_{i j}\right)+\beta_{2}\left(R_{i j}\right)+\beta_{3}\left(\text { year }_{i j}\right) \\
& +\sum_{j=2}^{23} a_{j}\left(D_{i j}\right)+\varepsilon_{i j} .
\end{aligned}
$$

In contrast, to explicitly evaluate the contribution of districts, we used generalized linear models (GLM) (2) with districts as binary dummy variables: 
$\stackrel{1}{1} \underset{89^{\circ} \mathrm{E}}{\stackrel{1}{9} \mathrm{E}}$

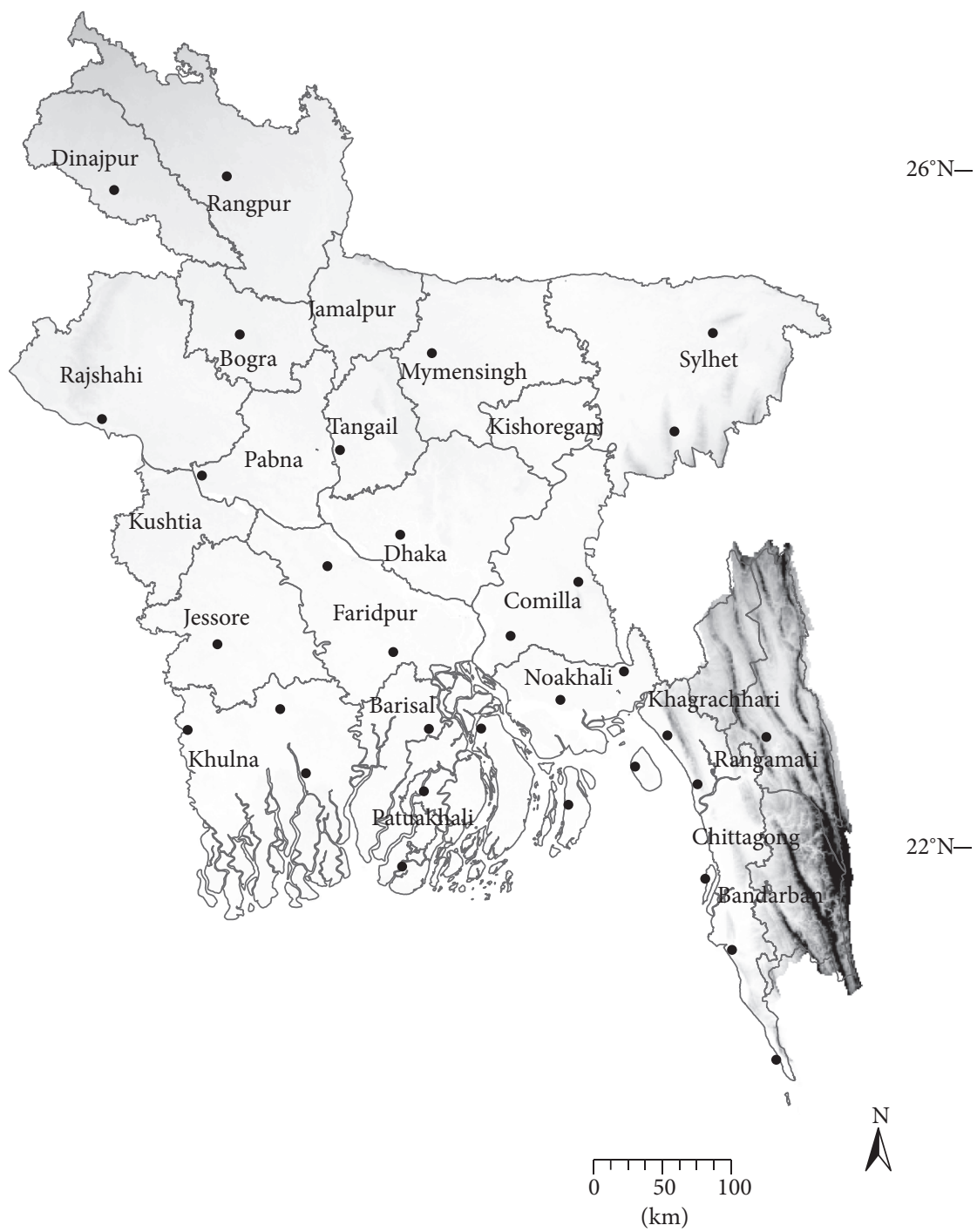

High
Low

FIGURE 1: Bangladesh's 23 greater districts used in the present study and a Digital Elevation Model (DEM) presenting the topographical landscape. Locations of 31 climate stations (black circles) across Bangladesh are also shown.

$$
\begin{aligned}
Y_{i j}= & \beta_{0}+\sum_{j=1}^{23} \beta_{1 j}\left(T_{i j}: D_{i j}\right)+\sum_{j=1}^{23} \beta_{2 j}\left(R_{i j}: D_{i j}\right) \\
& +\sum_{j=1}^{23} \beta_{3 j}\left(\text { year }_{i j}: D_{i j}\right)+\sum_{j=2}^{23} \beta_{4 j}\left(D_{i j}\right)+\varepsilon_{i j} .
\end{aligned}
$$

In both model types, $Y$ denotes the rice yield for the respective ecotypes, $i$ represents the different years in the study (e.g., 1981-2010), and $j$ represents the 23 greater districts in the models. The model coefficients $\beta$ and $a$ signify the fixed and random effects, respectively, and $\varepsilon$ denotes the error term. The independent variables in the models are average temperature $(T)$, rainfall $(R)$, and districts $(D)$ for the respective ecotype growing period. The control for unobserved temporal effects was time (year) as an explanatory variable in both models. In the models, using both districts $(D)$ and time (year) as a variable helped us to omit the effects of the regional variability which may be specific to a certain year or region due to time-variant factors such as disasters, land use intensification, 
TABLE 1: Summary statistics of the rice yields and growing period's average temperature and rainfall for three ecotypes.

\begin{tabular}{|c|c|c|c|c|c|c|c|c|c|}
\hline \multirow{3}{*}{ Statistics } & \multicolumn{9}{|c|}{ Variables } \\
\hline & \multicolumn{3}{|c|}{ Rice yield (t/ha) } & \multicolumn{3}{|c|}{ Temperature $\left({ }^{\circ} \mathrm{C}\right)$} & \multicolumn{3}{|c|}{ Rainfall (mm) } \\
\hline & Aus & Aman & Boro & Aus & Aman & Boro & Aus & Aman & Boro \\
\hline Mean & 1.32 & 1.73 & 2.79 & 28.11 & 27.87 & 23.46 & 1777 & 1850 & 465 \\
\hline Std. dev. & 0.39 & 0.45 & 0.63 & 0.47 & 0.32 & 0.62 & 477 & 497 & 185 \\
\hline Maximum & 2.44 & 2.79 & 4.29 & 29.40 & 28.66 & 25.23 & 3211 & 3392 & 1338 \\
\hline Minimum & 0.61 & 0.69 & 1.03 & 26.55 & 27.03 & 21.77 & 1034 & 898 & 110 \\
\hline
\end{tabular}

major improvements in technology, and government incentives and time invariant district specific characteristics such as the calibre of the soil, topography, and physiography.

We ran several diagnostic tests using $R$ statistical packages to develop our models. For this we typically considered the yield data for each rice ecotype individually, including the average seasonal temperature and rainfall variables for the respective ecotype. First, we checked the distribution of both dependent and independent variables for each ecotype used in the model by using the ladder approach developed by Tukey [30]; finding no transformation was required for any variable. Secondly, we assessed the stationarity of these variables for all the ecotypes by following the Augmented Dickey-Fuller (ADF) test [31] and all variables were stationary. Therefore, the GLM models can be applied to district data without preprocessing. Third, we evaluated the colinearity between temperature and rainfall for each season in the LMM models. The resultant $R^{2}$ was insignificant for all ecotypes.

To assess the overall performance of the models, we estimated a pseudo-R-squared value for generalized mixedeffect models using the "r.squaredGLMM" function from the MuMIn package [32]. We report both the marginal and conditional $R^{2}$ estimates to distinguish the variance explained for fixed effects compared to overall fixed and random factors in the models, respectively.

In order to assess the spatial pattern of rice yield changes across Bangladesh, as affected by a temperature increase, we applied a temperature increase $(\Delta T)$ to the GLM models by using the standardized relative changes equation (3). These changes are the product of the temperature coefficients $\beta_{1 j}$ from GLM models for the separate ecotypes multiplied by $\Delta T=1$, to assess the impact of a $1^{\circ} \mathrm{C}$ temperature increase. Standardized rice yield changes $\left(\Delta y_{j}\right)$ for all $j$ districts are estimated as

$$
\Delta y_{j}=\Delta T * \beta_{1 j}
$$

\section{Results}

3.1. Summary Statistics. The summary statistics of rice yields are presented in Table 1 . This table illustrates the fundamental characteristics of rice yield and climatic variables (temperature and rainfall) during the three rice-growing periods in Bangladesh over 30 years. The highest mean value is observed for Boro yield. The average temperature for the Aus growing period is the highest of the three growing periods. The Boro growing period receives less rainfall than the Aus and Aman periods. However, both rice yield and growing period climatic variables vary across Bangladesh and the following sections describe the spatiotemporal variations of these variables during the study period.

3.2. Spatiotemporal Variations of Rice Yields for the Three Ecotypes. The average rice yield varies across Bangladesh for the three ecotypes (Figure 2). Khulna, Chittagong, and Khagrachari were the highest yielding Aus regions in Bangladesh (Figure 2(a)). The average Aus yield for these districts was 1.54 to $1.90 \mathrm{t} / \mathrm{ha}$. Other areas with high Aus yields are Rajshahi, Bogra, Kushtia, Sylhet, Kishoreganj, Comilla, Rangamati, and Bandarban. Areas with low Aus yields (on average 0.81 to $1.32 \mathrm{t} / \mathrm{ha}$ ) are mostly in the middle of the country. The Chittagong hill tracts (Chittagong, Khagrachhari, Rangamati, and Bandarban) were observed to have the highest average yield of Aman, 1.97 to $2.50 \mathrm{t} / \mathrm{ha}$, during the study period (Figure 2(b)). Most of the western districts, including Rangpur, Bogra, Rajshahi, Kushtia, Jessore, and Khulna, along with Sylhet in the East, showed 1.60 to 1.97 t/ha Aman yield over the period. The remaining areas had low Aman yields: on average 1.14 to $1.60 \mathrm{t} / \mathrm{ha}$. The regions with the highest yield of Boro rice (on average 3.04 to $3.40 \mathrm{t} / \mathrm{ha}$ ) were Dhaka, Faridpur, Jessore, Kushtia, and Rajshahi (Figure 2(c)). On the other hand, all districts associated with the coast and Chittagong hill tracts had the lowest Boro yield: on average 1.53 to $2.88 \mathrm{t} / \mathrm{ha}$. Other districts, including Pabna, Tangail, Jamalpur, Mymensingh, Comilla, and Noakhali, had medium Boro yield (on average 2.88 to $3.04 \mathrm{t} / \mathrm{ha}$ ).

Temporal data on the rice yield in Bangladesh is available from 1972 and shows an increase for all ecotypes during the period 1972 to 2010 (Figure 3). Of the three varieties of rice considered in the present study, Boro yield significantly increased from 1972 to 2010, when compared with the Aus and Aman yields. In 1972, the average Boro yield was 2.01 t/ha but this rose to $3.7 \mathrm{t} /$ ha in 2010 . The Aman yield fluctuated over the period but overall showed a gradual increase from $1.05 \mathrm{t} /$ ha in 1972 to $2.19 \mathrm{t} /$ ha in 2010 . The Aus yield increased slowly during this period from $0.78 \mathrm{t} / \mathrm{ha}$ in 1972 to $1.64 \mathrm{t} / \mathrm{ha}$ in 2010.

3.3. Climate Variability in Different Rice-Growing Seasons. Temperature and rainfall vary across the Bangladesh for the different rice-growing seasons (Figure 4). During the Aus growing season (March to August) most of the north western part of the country had high average temperatures (on average 28.04 to $28.74^{\circ} \mathrm{C}$ ) but received relatively low rainfall (on average 1228 to $1715 \mathrm{~mm}$ ). For the Aman growing season (June to November), the western areas had high temperatures 

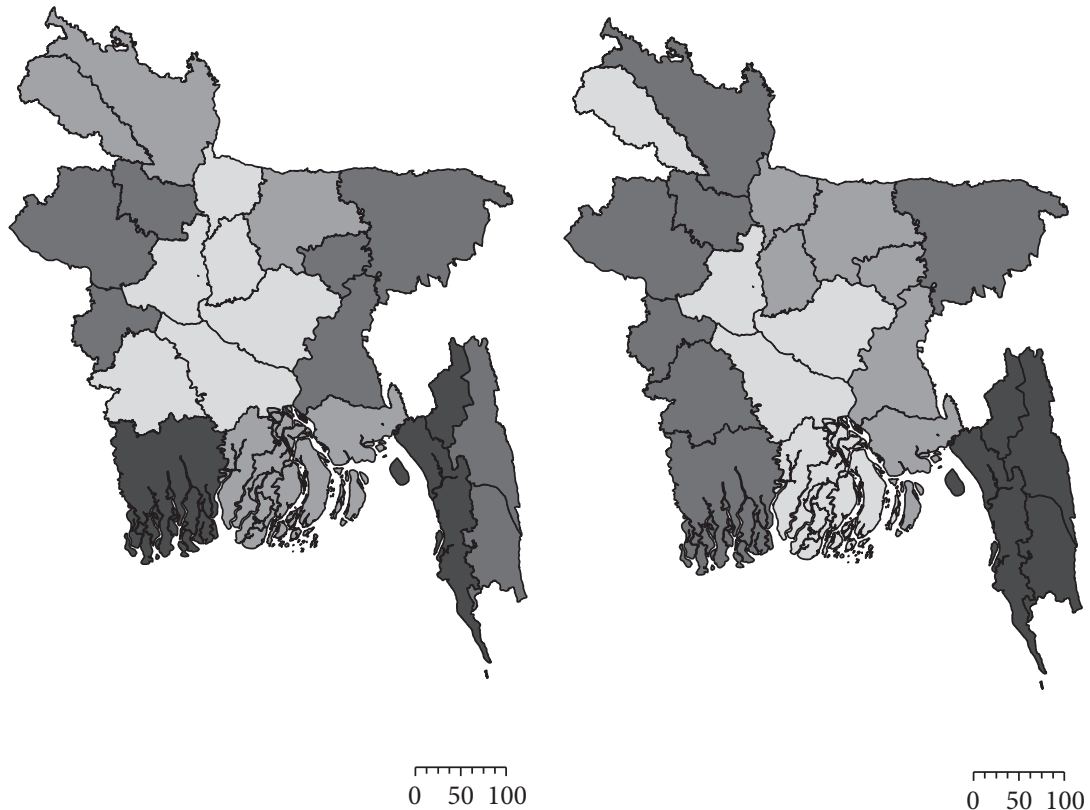

$(\mathrm{km})$
$0 \quad 50 \quad 100$

$(\mathrm{km})$

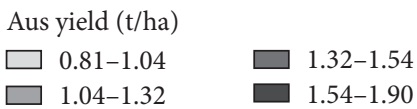

(a)

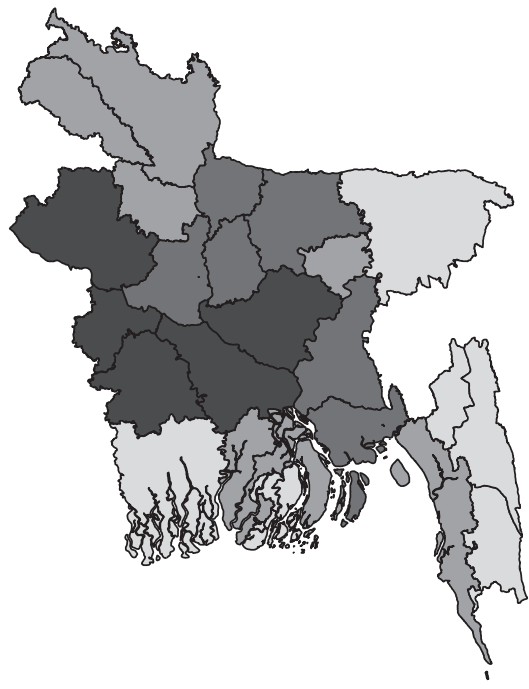

$0 \quad 50 \quad 100$

(km)

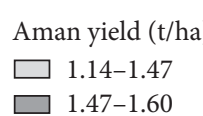

$\square$ 1.14-1.47
$\square \quad 1.47-1.60$

Boro yield (t/ha)

$\square$ 1.53-2.59 2.88-3.04 $\square$ 1.97-2.50

(b)
$3.04-3.40$

(c)

FIGURE 2: The spatial distribution of rice yield (t/ha) in Bangladesh averaged over the 1981-2010 period; classes represent quartiles; (a) Aus yield, (b) Aman yield, and (c) Boro yield.

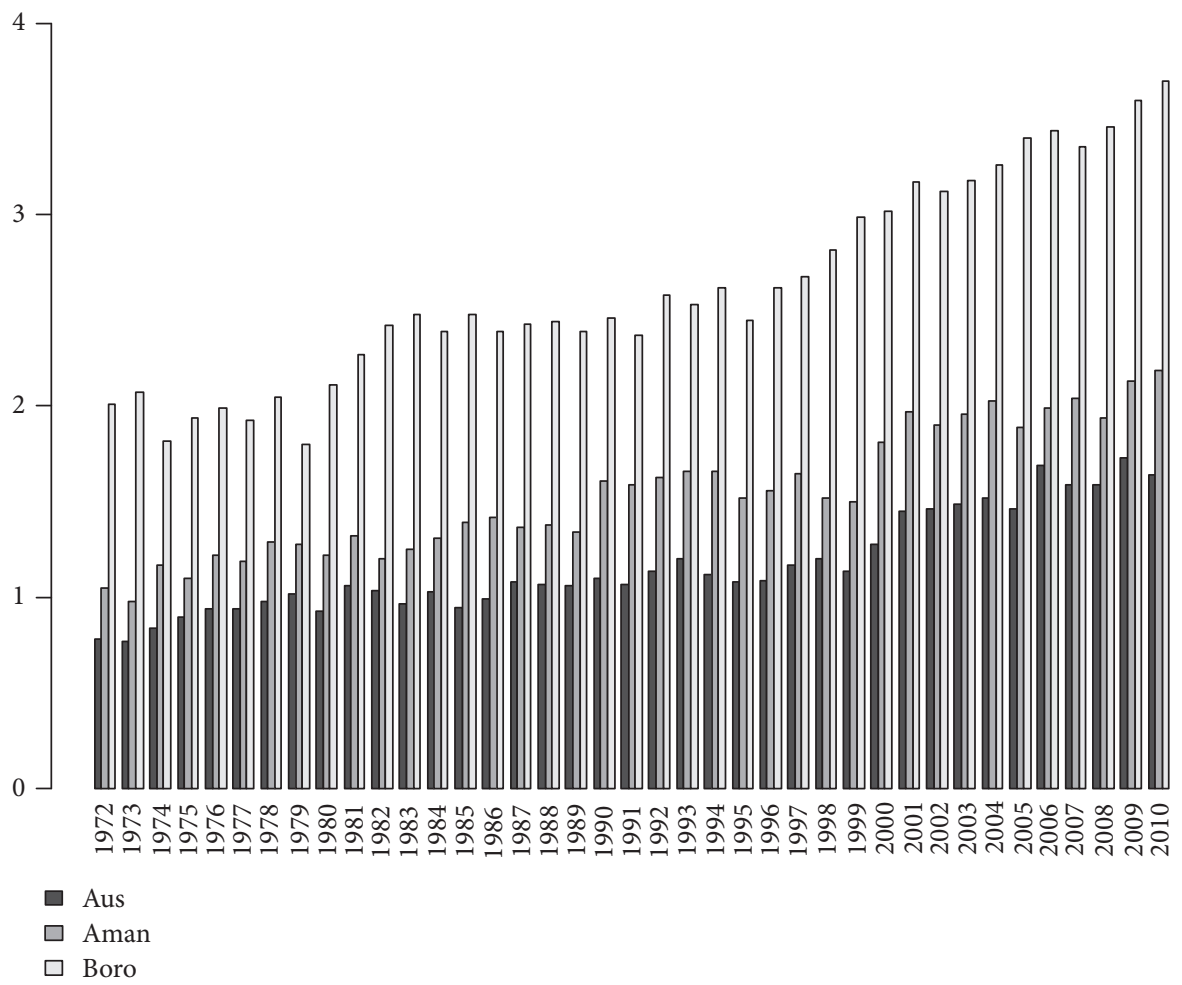

Figure 3: The temporal trend in rice yield ( $\mathrm{t} / \mathrm{ha}$ ) for three rice ecotypes during the 1972-2010 period in Bangladesh. 

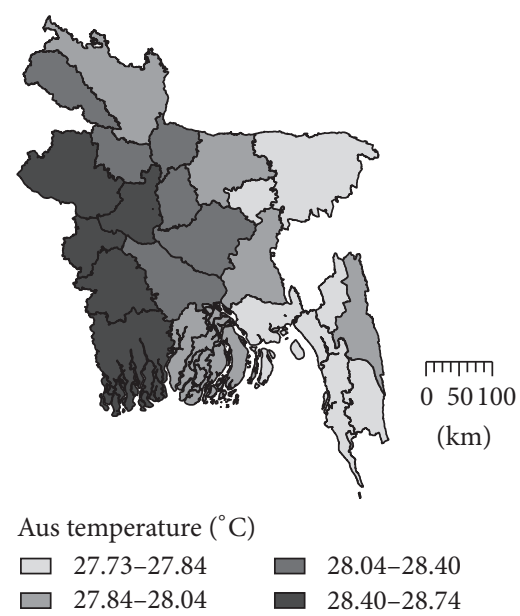

(a)
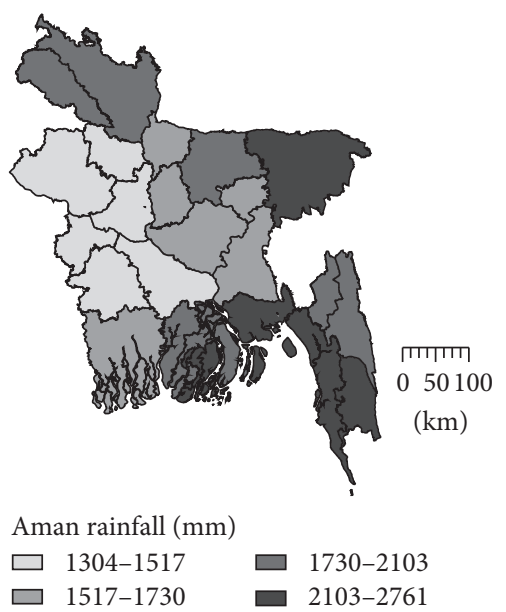

(d)
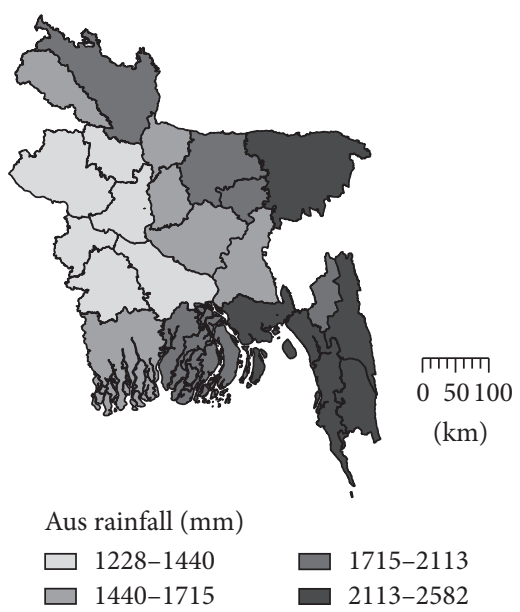

(b)
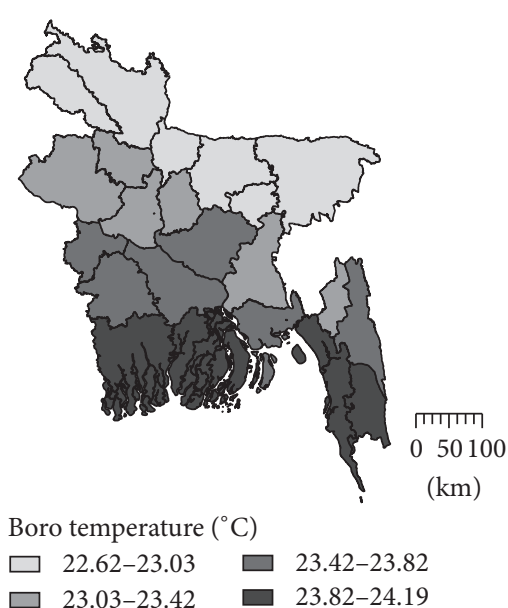

(e)
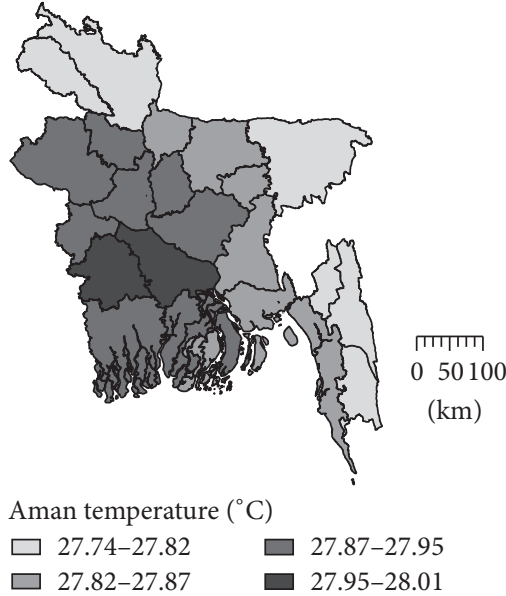

(c)

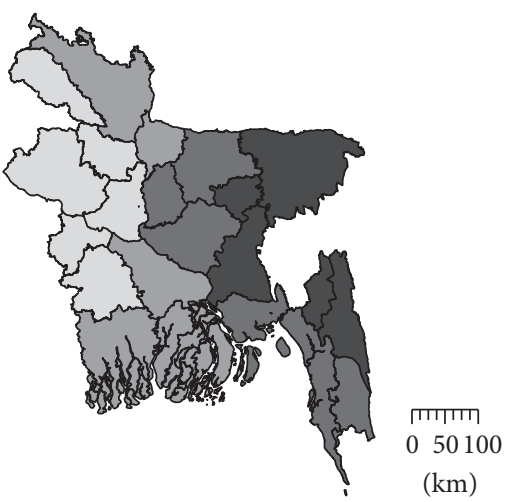

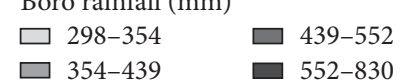

(f)

Figure 4: The spatial distribution of temperature $\left({ }^{\circ} \mathrm{C}\right)$ and rainfall $(\mathrm{mm})$ of three rice-growing periods in Bangladesh, averaged over the 1981-2010 period for three rice-growing seasons; classes represent quartiles; (a) Aus temperature, (b) Aus rainfall, (c) Aman temperature, (d) Aman rainfall, (e) Boro temperature, and (f) Boro rainfall.

with an average of 27.87 to $28.01^{\circ} \mathrm{C}$ during the study period. However, these areas received lower rainfall (on average 1304 to $1730 \mathrm{~mm}$ ) compared with the eastern areas (on average 1730 to $2761 \mathrm{~mm}$ ).

In the Boro growing season (December to May), most of the southern areas and Chittagong hill tracts in Bangladesh had high temperatures (on average 23.42 to $24.19^{\circ} \mathrm{C}$ ). During this season the southern and entire north western areas of Bangladesh received low rainfall (on average 298 to $439 \mathrm{~mm}$ ), whereas the eastern areas and Chittagong hill tract received high rainfall (on average 439 to $830 \mathrm{~mm}$ ). To understand the quantitative justification of climate impacts on Aus, Aman, and Boro ecotypes individually, we estimated statistical models.

3.4. Climate Impacts on Aus Yield. The linear mixed model results (Table 2) show the temperature and rainfall effects on Aus yield in Bangladesh nationally. These results show that temperature does not influence Aus yield, whereas rainfall has a slightly positive correlation with rice yield $(p<0.08)$.
The marginal and conditional $R^{2}$ values are 0.12 and 0.75 , respectively. The fixed effects factors only account for $12 \%$ of the variance explained; the full model that includes districts as a random effect explains $75 \%$. This demonstrates that the improvement of $R^{2}$ is due to spatial differences.

3.5. Climate Impacts on Aman Yield. The influence of the growing season average climatic variables on the Aman rice yield is shown in Table 3. The impacts of both temperature and rainfall are negative, with temperature showing high significance at a $p$ value $<0.001$. The rainfall effect is not significant with a $p$ value of 0.28 . Total $26 \%\left(\right.$ marginal $R^{2}$ ) and $90 \%$ (overall $R^{2}$ ) of the variability in Aman rice yield is explained by the fixed factors and both fixed and random factors used in the model, respectively.

3.6. Climate Impacts on Boro Yield. The LMM results show the contributions of the climatic variables on the Boro yield and are presented in Table 4. Increased temperature has a positive impact on Boro yield ( $p$ value $=0.05$ ), whereas 
TABLE 2: Results of mixed model analysis forAus yield and climatic variables.

\begin{tabular}{lccc}
\hline Variables & Estimate & Standard error & $p$ value \\
\hline Intercept & -30.530 & 1.744 & $<0.001$ \\
Temperature & -0.003 & 0.023 & 0.882 \\
Rainfall & 0.000 & 0.000 & 0.078 \\
Year & 0.015 & 0.000 & $<0.001$ \\
\hline
\end{tabular}

TABLE 3: Results of mixed model analysis forAman yield and climatic variables.

\begin{tabular}{lccc}
\hline Variables & Estimate & Standard error & $p$ value \\
\hline Intercept & -56.052 & 1.376 & $<0.001$ \\
Temperature & -0.150 & 0.025 & $<0.001$ \\
Rainfall & -0.000 & 0.000 & 0.277 \\
Year & 0.031 & 0.000 & $<0.001$ \\
\hline
\end{tabular}

increased rainfall shows a small negative influence $(p<0.1)$. The fixed effects factors explain $49 \%$ of Boro yield variation with an overall $R^{2}$ value of $91 \%$.

3.7. Climate Impacts on Regional Rice Yield. The results from the GLM model demonstrate the individual impact of temperature and rainfall on regional rice yields for the three ecotypes (Table 5). In general, Aus shows both positive and negative influence of temperature in different districts, and Aman is mostly negative, whereas Boro has a more positive response to temperature. The impact of seasonal rainfall is negligible for the three ecotypes in all districts. As expected, there is a significant change of yield over time in all districts due to changes or improvements in regional rice cultivation management during the time of the study.

The coefficients of the temperature effects on regional Aus yield are positive in nine districts. The $p$ values for two of these districts are statistically significant (Comilla and Khulna). The impact is negative in the other 14 districts, although the results for these districts are not strong enough to show statistical significance.

The coefficients of the temperature effects on regional Aman yields are negative in 20 districts. The $p$ values for eight of these districts are statistically significant: Bandarban, Bogra, Dinajpur, Khagrachari, Kishoreganj, Mymensingh, Pabna, and Rangpur. The impact is positive in the remaining three districts; however, the results for these districts are not statistically significant.

The impact of temperature is positive for Boro yield in 18 districts with $p$ values for only three districts being statistically significant (Dinajpur, Jamalpur, and Kishoregong). The temperature effects are negative in five districts, with none being statistically significant.

\subsection{Regional Variation of Rice Yield Changes due to a $1^{\circ} \mathrm{C}$ Tem-} perature Increase. The impact of the growing season average temperature on national rice yields for different ecotypes in the LMM models can be visualised by calculating rice yield changes in the model rice yield due to a $1^{\circ} \mathrm{C}$ temperature increase in Bangladesh. Figure 5 illustrates the rice yield
TABLE 4: Results of mixed model analysis for Boro yield and climatic variables.

\begin{tabular}{lccc}
\hline Variables & Estimate & Standard error & $p$ value \\
\hline Intercept & -97.839 & 1.726 & $<0.001$ \\
Temperature & 0.034 & 0.017 & 0.050 \\
Rainfall & -0.000 & 0.000 & 0.088 \\
Year & 0.050 & 0.000 & $<0.001$ \\
\hline
\end{tabular}

TABLE 5: Results of the generalized linear model analysis showing the coefficient of temperature effects on Aus, Aman, and Boro yields in the greater districts in Bangladesh.

\begin{tabular}{lccc}
\hline Districts & Aus & Aman & Boro \\
\hline Bandarban & -0.06 & -0.17 & -0.04 \\
Barishal & 0.05 & -0.00 & 0.07 \\
Bogra & -0.14 & $-0.23^{*}$ & 0.07 \\
Chittagong & -0.13 & -0.16 & -0.07 \\
Comilla & 0.22 & -0.12 & 0.06 \\
Dhaka & 0.02 & -0.15 & 0.06 \\
Dinajpur & -0.08 & $-0.33^{* * *}$ & $0.20^{* * *}$ \\
Faridpur & -0.11 & -0.02 & 0.05 \\
Jamalpur & 0.01 & -0.16 & 0.12 \\
Jessore & -0.03 & 0.06 & 0.00 \\
Khagrachari & -0.11 & $-0.32^{* *}$ & 0.10 \\
Khulna & $0.24^{*}$ & 0.19 & 0.02 \\
Kishoregong & -0.00 & $-0.36^{* * *}$ & 0.13 \\
Kushtia & -0.06 & -0.09 & -0.04 \\
Mymensingh & -0.05 & $-0.33^{* * *}$ & -0.00 \\
Noakhali & 0.14 & 0.03 & 0.00 \\
Pabna & -0.06 & $-0.21^{*}$ & 0.08 \\
Patuakhali & 0.03 & -0.16 & -0.07 \\
Rajshahi & -0.04 & -0.11 & 0.05 \\
Rangamati & 0.01 & -0.04 & 0.06 \\
Rangpur & -0.09 & -0.11 & 0.09 \\
Sylhet & 0.00 & $-0.24^{* *}$ & 0.00 \\
Tangail & -0.03 & -0.04 & 0.05 \\
\hline
\end{tabular}

$10 \%$ level of significance; ${ }^{*} 5 \%$ level of significance; ${ }^{* *} 1 \%$ level of significance; ${ }^{* * *} 0.1 \%$ level of significance.

changes in Bangladesh for three ecotypes nationally. The Aman yield change $(-0.15 \mathrm{t} / \mathrm{ha})$ is higher than the Aus and Boro yield changes, $-0.003 \mathrm{t} / \mathrm{ha}$ and $0.03 \mathrm{t} / \mathrm{ha}$, respectively. This result demonstrates that, in the future, the national Aman yield may be more vulnerable to temperature increases than the Aus and Boro. Boro yield even shows a small increase with temperature.

The regional variations of changes in the modelled Aus, Aman, and Boro rice yields for a $1^{\circ} \mathrm{C}$ temperature increase are shown in Figure 6. The effect of seasonal temperature on regional Aus rice yield is small in many districts, as is shown by the yellow areas on the map (Figure 6, Aus). Aus yield decreases with temperature in four districts, Borga $(-0.14 \mathrm{t} / \mathrm{ha})$; Chittagong $(-0.13 \mathrm{t} / \mathrm{ha})$; Faridpur $(-0.11 \mathrm{t} / \mathrm{ha})$; and Khargrachari $(-0.11 \mathrm{t} / \mathrm{ha})$, and increases in seven districts. The largest increases can be observed in Comilla 


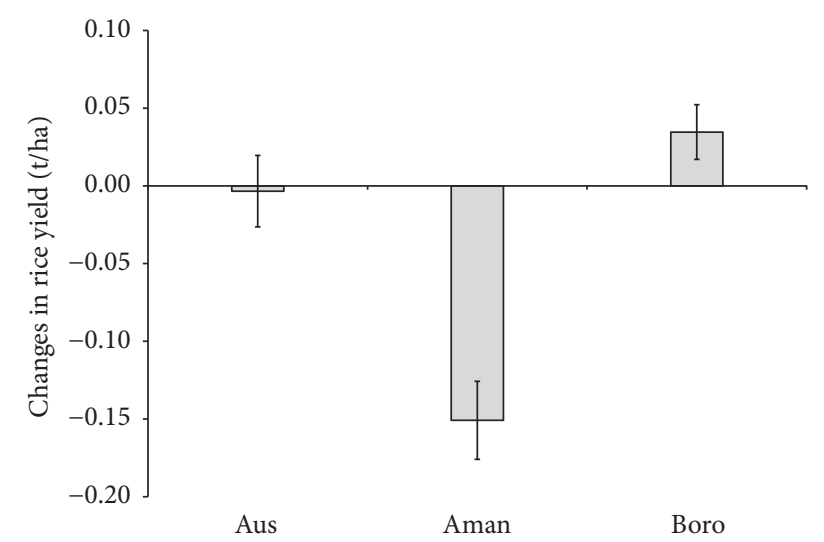

FIGURE 5: Changes in the modelled rice yield ( $\mathrm{t} / \mathrm{ha}$ ) that arise from a $1^{\circ} \mathrm{C}$ temperature increase.

(0.22t/ha) and Khulna ( $0.24 \mathrm{t} / \mathrm{ha})$ with a statistically significant temperature effect at $5 \%$ and $1 \%$ levels, respectively (Table 5).

The Aman yield shows a decrease with increasing temperature in all districts except Khulna, Jessore, and Noakhali (Figure 6, Aman). The temperature effect is statistically significant in Dinajpur, Kishoreganj, and Mymensingh at the $0.1 \%$ level. The magnitude of Aman yield decrease is $0.33 \mathrm{t} / \mathrm{ha}$, $0.34 \mathrm{t} / \mathrm{ha}$, and $0.33 \mathrm{t} / \mathrm{ha}$, respectively, in these districts. Similarly, Aman yield will decrease in Khagrachari (0.22 t/ha) and in Sylhet $(0.24 \mathrm{t} / \mathrm{ha})$ at a $1 \%$ level of significance and in Bogra $(0.23 \mathrm{t} / \mathrm{ha})$ and Pabna $(0.21 \mathrm{t} / \mathrm{ha})$ at the $5 \%$ level of significance (Table 5).

Boro yield, in contrast, exhibits an increase in most districts (Figure 6, Boro). The temperature effect is statistically significant for Boro yield in the three districts of Dinajpur, Kishoreganj, and Jamalpur, where Boro yield increases at $0.20 \mathrm{t} / \mathrm{ha}, 0.13 \mathrm{t} / \mathrm{ha}$, and $0.12 \mathrm{t} / \mathrm{ha}$, respectively. The Boro yield decreases with temperature in Kushtia, Chittagong, Bandarban, Sylhet, Mymensingh, Jessore, and Noakhali districts; however, the temperature effects are statistically insignificant (Table 5).

\section{Discussion}

The present study has analysed the spatially variable climate impact on the rice yield for three ecotypes in Bangladesh using 30 years of historical records. There were strong differences in the growing season temperature and rainfall for the three ecotypes. We investigated the relationship between the climatic variables and the government rice yield statistics and our analysis showed that climatic variables have a substantial influence on rice yield. The temperature changes correlated more strongly with the rice yield than the rainfall. In addition, our results reveal different climatic influences for the three ecotypes and strong regional variations of rice yields across the country.

4.1. Regional Variability of Rice Yield and Climatic Variables. The results from our analysis of the spatiotemporal changes to the rice yield indicated that rice yield varied in different areas for Aus, Aman, and Boro. Overall, there was a significant spatial pattern in the rice yield for these ecotypes, with the Aus and Aman yields being more favorable in the north western, eastern, and Chittagong hill tracts in Bangladesh than in other areas. Most of the central part of the country had low Aus and Aman yields. In contrast, Boro was mostly grown in the western and central parts of the country. There are many possible factors contributing to rice yield variations across Bangladesh. These include many natural variables (e.g., topography, soil, drought/flood, and climatic conditions), management factors (e.g., irrigation, use of fertilizer/pesticides), and agricultural technologies (e.g., ploughing methods and the use of high yielding varieties and hybrid seed).

The present study shows that rice yield has increased over the period from 1971 to 2010 and that during this period Boro yield has increased to a greater extent, when compared with Aus and Aman yields. This increase in Boro yield in Bangladesh is attributed to the shift in Boro production from being rain-fed to using irrigation during the dry season [33, 34].

4.2. Spatially Variable Climate Effects. To assess the relative importance of the climatic variables on the rice yield, particularly temperature and rainfall, the coefficients resulting from the LMM model for each rice ecotype were used. Overall, our results demonstrate that temperature has a much stronger impact on rice yield than rainfall. These findings of the impact of climate on rice yield variability are consistent with the findings of the previous empirical study by Sarker et al. [26], using the time series data alone from the historic records to assess the impact of climate on rice yield nationally. Evaluating regional variations in the GLM model, we found significant differences in the regional estimates, in both sign and size.

Our study shows a spatially variable climate impact on rice yield for the different ecotypes. The LMM model suggests an inconclusive influence of climate factors on Aus, a negative effect of temperature on Aman, and a positive influence of temperature on Boro. Others have found a negative temperature impact on Aus, $[21,24]$ but our empirical study does not confirm these effects. On the other hand, rainfall impacted on the Aus yield positively, which is also consistent with previous results $[26,27]$. Secondly, our results demonstrate that the Aman yield would be the most susceptible to climate change of the three rice ecotypes. We found a statistically significantly negative relationship between average temperature and Aman yield. These results are consistent with the results of Amin et al. [17]. Similar results were found in the previous study based on climate change scenarios by MoEF [19], which indicate that rice yield variability would be higher for Aman due to climatic change. Thirdly, the growing season temperature showed a statistically significant positive impact on Boro yield. However, the impacts of temperature on the Boro yield were not consistent in previous studies, with some authors finding a positive impact for minimum temperatures $[17,26]$ and others finding a negative impact for maximum temperatures $[26,27]$. Our results show that the impact of rainfall on the Boro growing season was low, as expected, 

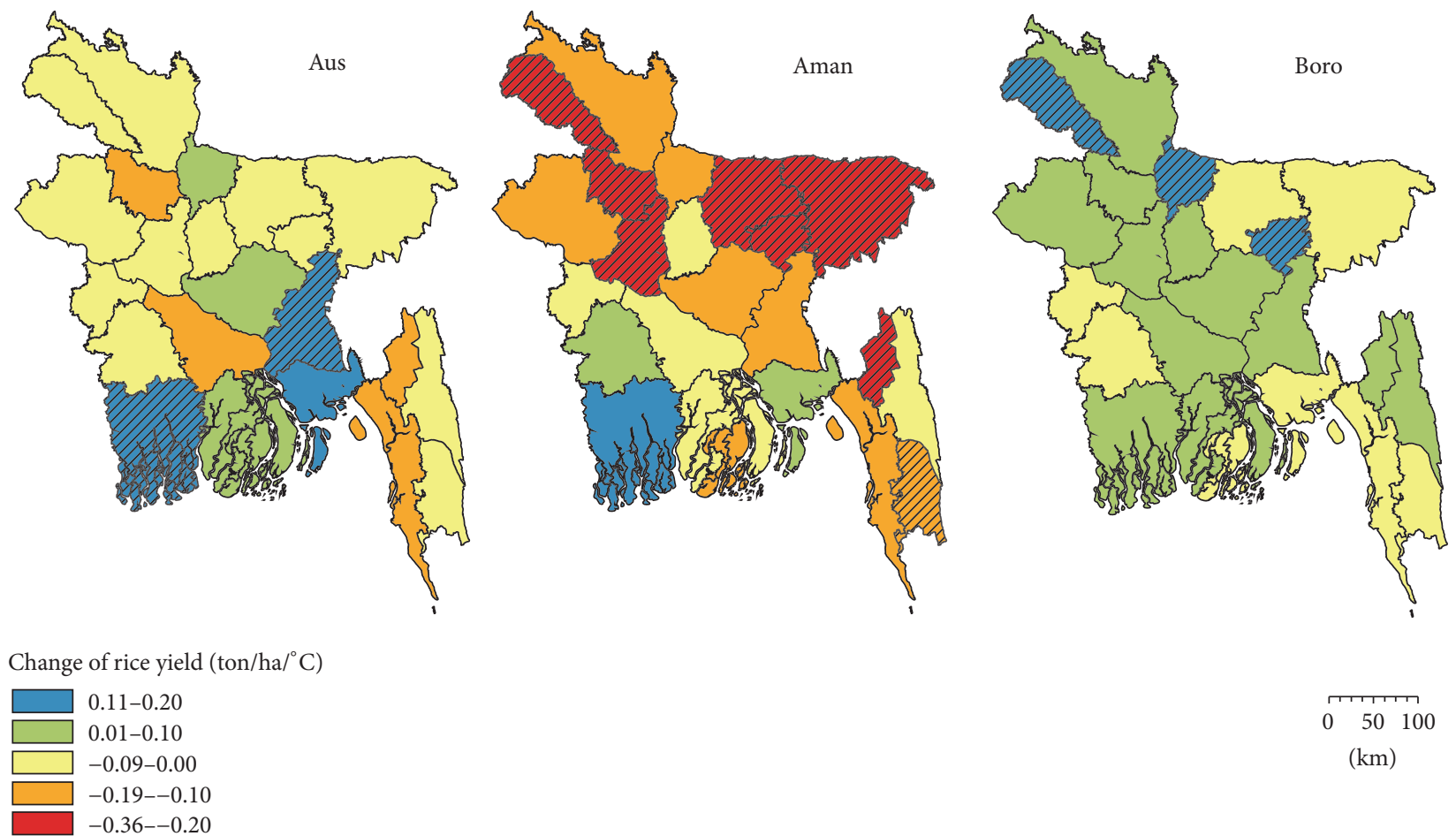

$(\mathrm{km})$

Figure 6: Regional variations in changes to the modelled rice yield ( $\mathrm{t} / \mathrm{ha}$ ) for three ecotypes Aus, Aman, and Boro due to a $1^{\circ} \mathrm{C}$ temperature increase across Bangladesh. Districts with statistically significant temperature effects are highlighted with a diagonal line pattern.

since the Boro growing season usually receives little rainfall $[23,27]$. Noticeable for all models is a strong explanatory power of districts in the models, as indicated by the high overall $R^{2}$ compared to the marginal $R^{2}$ of only considering the fixed effects. This indicates strong regional differences addressed below.

4.3. Regional Variations in Future Rice Yield Changes. The present study shows the regional rice yield changes in the greater districts of Bangladesh. Our results from the GLM model (Table 5) are based on the historic records of last 30 years and were used to predict regional rice yield changes in the future due to $1^{\circ} \mathrm{C}$ temperature increase. Figure 6 presents the expected regional variations of rice yield changes for Aus, Aman, and Boro for this scenario. The Aman rice yield may decrease in most of the districts. Previous simulation studies produced similar results, showing that Aman rice yield may decline in many areas in the country [21, 24, 27]. Similarly, increasing growing season average temperatures negatively impacted Aus rice yield in many districts, as found in previous studies [21, 24, 27]. Boro yield will benefit from increases in temperature, as also found by Basak et al. [23]. The present study did not show the rainfall effects on regional rice yields as these effects were not significant in all districts, with very little or no impact (the coefficients were too small to consider). Ruane et al. [24] also indicated that the regional Aus and Aman yields were not impacted by the growing season rainfall levels. Boro yield was typically influenced by irrigation management, rather than by the dry season's rainfall regimes $[9,34]$.
4.4. Data Limitations, Uncertainties, and Future Research. Our study focuses on statistical analyses using government records on rice yields and climate at a spatiotemporal level, with considerable uncertainties. We found a noticeable effect of time in the GLM model, clearly indicating that there are several unobserved factors affecting rice yield. However, controlling for these unobserved factors was not possible because spatiotemporal data on many natural and management variables was unavailable. For instance, irrigation demand or other variables associated with rice cultivation were not recorded at regional levels for the different ecotypes. Groundwater data has been collected but could not be used in our analysis because detailed information on the use of ground water for irrigation to produce rice for different ecotypes was not available.

Moreover, time series data on the use of pesticides, fertilizer, and improved seeds are limited for particular years. We tried to develop soil data on the basis of the category of soil profile including soil nutrients, soil moisture, and soil organic matter, at aggregated districts level by using GIS techniques. However, we found that the soil data was too variable for different categories in various districts to use in the models. The present study considers climatic variables, particularly the average growing season temperature and rainfall. However, the impacts of extreme weather events, including drought and floods, which may become more frequent in many districts [35,36], were not incorporated into the present study due to the lack of spatiotemporal data on these elements. 
Climate impacts on agriculture are uncertain because of the complex processes of both direct and indirect effects of weather on the rice yield $[16,17,26]$ that may vary for different stages of growing seasons for all ecotypes [23, 25]. Moreover, spatially weighted growing season average climate data at district level as used in the present study ignores local microclimate conditions. There is already evidence that a shortening of the rainy season, or heavy rainfall, high temperatures, cold waves, or more frequent dry spells can all influence rice yields locally in certain districts in Bangladesh $[37,38]$. Disasters [35, 36], regional management $[1,39]$, and local microclimatic conditions [37] have become important indicators of change, which need further local investigation.

4.5. Policy Implications for Food Security in Terms of Climate Change. Our study modelled regional rice yield changes for a $1^{\circ} \mathrm{C}$ temperature increase across Bangladesh. The study illustrates a substantial variation in regional rice yield sensitivity to temperature for different ecotypes across the 23 greater districts of Bangladesh. Although climate change influence had been assessed previously at a broad scale in Bangladesh $[16,24]$, the district-level assessment in this study will help to understand more details about future rice yield changes and to evaluate necessary actions with different districts potentially employing different adaptation measures. Therefore, the present study cautions against country or state level general adaptation measures for climate change [19], which may be ineffective, and consequently suggests that there is a requirement for region-specific adaptation policies. However, the various adaptation measures should be monitored by the agriculture research and extension services in each district. At present, farmers are trying to devise locally appropriate practices for rice cultivation in many districts of Bangladesh in order to deal with local climate variability [37]. Crop models suggest that adjustments to planting dates would increase rice yields in many districts [23, 25]. Public and private investment in action-oriented adaptive research is required to support regional rice agriculture in the face of climate change. Technological improvements for continued dissemination of research to local farmers are necessary in different districts. Priority might be given to research on varietal improvement, particularly in terms of temperature or drought tolerant rice varieties. Region-specific adaptation measures, along with well-timed local climate information, will help farmers to cope with uncertain climate dependencies across Bangladesh. Furthermore, various regional developments, including sustainable irrigation combining use the of both groundwater and surface water [1,39], moving rice production to other less intensively cultivated areas [2], and various improved management practices are all needed to increase rice yields in various districts, which will in turn improve food security in the country.

\section{Conclusions}

The objective of the present study was to understand the spatially variable effects of climate change on rice yields for three ecotypes across Bangladesh. Based on past yield observation records, the overall findings reveal that the impact of climatic variables on rice yields is ecotype specific. The results demonstrate that Aman yield may be the worst affected ecotype by a future temperature increase, when compared with the Aus and Boro yields. There is a substantial spatial variability of rice yield sensitivity to a $1^{\circ} \mathrm{C}$ temperature increase amongst the 23 greater districts. Temperature has adversely impacted Aus and Aman yields in most of the districts compared to an overall positive temperature response of Boro yield. Given this sensitivity to regional rice yield variations, ecotype specific adaptation strategies need to be adopted urgently in different districts to combat future climate change. Priority might be given to the disadvantaged districts where the rice yield will decrease noticeably. Adaptation strategies include the improved dissemination of climate information along with the development and introduction of new temperaturetolerant varieties in these districts. However, substantial use of new varieties in different districts needs to be monitored continuously. For this, adequate investment and publicprivate sector involvement will be necessary for a significant time period. The spatially aggregated time series data used in the present study has primarily focused on climate variables alone. Due to a lack of data, the study did not consider other important variables, which contributed to higher yields in many districts during the study period. Therefore, future research should focus on both climate change and other variables to capture a more robust picture of regional rice yields for the ecotypes favored across Bangladesh.

\section{Conflicts of Interest}

The authors declare that there are no conflicts of interest regarding the publication of this paper.

\section{Authors' Contributions}

Iffat Ara conceived the study idea, collected data, performed analysis and interpreted the data, and wrote the manuscript. Megan Lewis revised the manuscript critically for important intellectual content. Bertram Ostendorf contributed to the analysis and provided a critical evaluation of the manuscript. All authors read and approved the final manuscript.

\section{Acknowledgments}

This research is funded by the Australian Government and the University of Adelaide through an International Postgraduate Research Scholarship (IPRS) and an Australian Postgraduate Award (APA) for the first author to pursue her Ph.D. Special thanks go to Ingrid Ahmer and Alison Jane-Hunter at the University of Adelaide for assisting in technical language editing. Acknowledgment is also made of the support from the Bangladesh Bureau of Statistics (BBS) and the Bangladesh Meteorological Department (BMD) in providing rice yield and climate data, respectively, both of which were used as the basis of this research.

\section{References}

[1] I. Ara, M. Lewis, and B. Ostendorf, "Spatio-temporal analysis of the impact of climate, cropping intensity and means 
of irrigation: an assessment on rice yield determinants in Bangladesh," Agriculture and Food Security, vol. 5, no. 1, pp. 1-11, 2016.

[2] M. Mainuddin and M. Kirby, "National food security in Bangladesh to 2050," Food Security, vol. 7, no. 3, pp. 633-646, 2015.

[3] D. D. Headey and J. Hoddinott, "Agriculture, nutrition and the green revolution in Bangladesh," Agricultural Systems, vol. 149, pp. 122-131, 2016.

[4] J. Furuya and O. Koyama, "Impacts of climatic change on world agricultural product markets: estimation of macro yield functions," Japan Agricultural Research Quarterly, vol. 39, no. 2, pp. 121-134, 2005.

[5] W. H. Yu, M. Alam, A. Hassan, A. S. Khan, A. C. Ruane, C. Rosenzweig et al., Climate Change Risks and Food Security in Bangladesh, 2010.

[6] W. Shi and F. Tao, "Vulnerability of African maize yield to climate change and variability during 1961-2010," Food Security, vol. 6, no. 4, pp. 471-481, 2014.

[7] Y. Qin, J. Liu, W. Shi, F. Tao, and H. Yan, "Spatial-temporal changes of cropland and climate potential productivity in northern China during 1990-2010," Food Security, vol. 5, no. 4, pp. 499-512, 2013.

[8] P. Belesky, "Regional governance, food security and rice reserves in East Asia," Global Food Security, vol. 3, no. 3-4, pp. 167-173, 2014.

[9] S. Shahid, "Impact of climate change on irrigation water demand of dry season Boro rice in northwest Bangladesh," Climatic Change, vol. 105, no. 3-4, pp. 433-453, 2011.

[10] BBS, Agricultural Statistical Year Book of Bangladesh, GoB, Dhaka, Bangladesh, 2010.

[11] FAO, Country Nutrition Paper Bangladesh, Rome, Italy, 2014.

[12] FAO, The state of food insecurity in the world, 2015, Rome, Italy, 2015.

[13] IRRI, International Rice Research Institute, 2010.

[14] GoB, Bangladesh Economic Review, Bangladesh Minitry of Finance, Dhaka, Bangladesh, 2010.

[15] MoFDM, National Food Policy, Ministry of Food and Disaster Management, GoB, Dhaka, Bangladesh, 2006.

[16] M. A. R. Sarker, K. Alam, and J. Gow, "Assessing the effects of climate change on rice yields: An econometric investigation using Bangladeshi panel data," Economic Analysis and Policy, vol. 44, no. 4, pp. 405-416, 2014.

[17] M. R. Amin, J. Zhang, and M. Yang, "Effects of climate change on the yield and cropping area of major food crops: a case of Bangladesh," Sustainability Science, vol. 7, no. 1, pp. 898-915, 2015.

[18] BBS, Agricultural Statistical Yearbook of Bangladesh, GoB, Dhaka, Bangladesh, 2012.

[19] MoEF, National Adaptation Programme of Action (NAPA), Ministry of Environment and Forest, GoB, Dhaka, Bangladesh, 2005.

[20] MoEF, Bangladesh Climate Change Strategy and Action Plan (BCCSAP), Ministry of Environment and Forest, GoB, Dhaka, Bangladesh, 2009.

[21] Z. Karim, S. Hussain, and M. Ahmed, "Assessing impacts of climatic variations on food grain production in Bangladesh," Water, Air, and Soil Pollution, vol. 92, no. 1, pp. 53-62, 1996.

[22] R. Mahmood, "Air temperature variations and rice productivity in bangladesh: a comparative study of the performance of the
YEILD and the CERES-rice models," Ecological Modelling, vol. 106, no. 2-3, pp. 201-212, 1998.

[23] J. K. Basak, M. A. Ali, M. N. Islam, and M. A. Rashid, "Assessment of the effect of climate change on boro rice production in Bangladesh using DSSAT model," Journal of Civil Engineering, vol. 38, no. 2, pp. 95-108, 2010.

[24] A. C. Ruane, D. C. Major, W. H. Yu et al., "Multi-factor impact analysis of agricultural production in Bangladesh with climate change," Global Environmental Change, vol. 23, no. 1, pp. 338350, 2013.

[25] R. Mahmood, M. Meo, D. R. Legates, and M. L. Morrissey, "The CERES-rice model-based estimates of potential monsoon season rainfed rice productivity in Bangladesh," Professional Geographer, vol. 55, no. 2, pp. 259-273, 2003.

[26] M. A. R. Sarker, K. Alam, and J. Gow, "Exploring the relationship between climate change and rice yield in Bangladesh: an analysis of time series data," Agricultural Systems, vol. 112, pp. 11-16, 2012.

[27] R. H. Rimi, S. H. Rahman, S. Karmakar, and S. G. Hussain, "Trend analysis of climate change and investigation on its probable impacts on rice production at Sathkhira, Bangladesh," Pakistan Journal Meteorol, vol. 6, pp. 37-50, 2009.

[28] M. W. Rahman and L. Parvin, "Impact of Irrigation on Food Security in Bangladesh for the Past Three Decades," Journal of Environmental Protection, vol. 1, pp. 40-49, 2009.

[29] BMD, Climate Database, Bangladesh Meteorological Department, Dhaka, Bangladesh, 2012.

[30] J. W. Tukey, Exploratory Data Analysis, Addition-Wesley, Massachusetts, Mass, USA, 1977.

[31] D. A. Dickey and W. A. Fuller, "Distribution of the Estimators for Autoregressive Time Series with a Unit Root," Journal of the American Statistical Association, vol. 74, no. 366, pp. 427-431, 1979.

[32] K. Barton, MuMIn: Multi-model inference, $\mathrm{R}$ package version 3.0.0, 2014

[33] MoA, Handbook of Agricultural Statistics, 2014.

[34] R. Rahman and M. S. Mondal, "Role of Water Resource Management in Ensuring Food Security," in Food Security and Risk Reduction in Bangladesh, U. Habiba, M. A. Abedin, A. W. R. Hassan, and R. Shaw, Eds., pp. 213-234, Springer, Tokyo, Japan, 2015.

[35] S. Shahid and H. Behrawan, "Drought risk assessment in the western part of Bangladesh," Natural Hazards, vol. 46, no. 3, pp. 391-413, 2008.

[36] M. M. Q. Mirza, "Global warming and changes in the probability of occurrence of floods in Bangladesh and implications," Global Environmental Change, vol. 12, no. 2, pp. 127-138, 2002.

[37] M. Alauddin and M. A. R. Sarker, "Climate change and farmlevel adaptation decisions and strategies in drought-prone and groundwater-depleted areas of Bangladesh: an empirical investigation," Ecological Economics, vol. 106, pp. 204-213, 2014.

[38] A. R. Sarker, K. Alam, and J. Gow, "Assessing the determinants of rice farmers' adaptation strategies to climate change in Bangladesh," International Journal of Climate Change Strategies and Management, vol. 5, no. 4, pp. 382-403, 2013.

[39] S. Shahid and M. K. Hazarika, "Groundwater drought in the northwestern districts of Bangladesh," Water Resources Management, vol. 24, no. 10, pp. 1989-2006, 2010. 


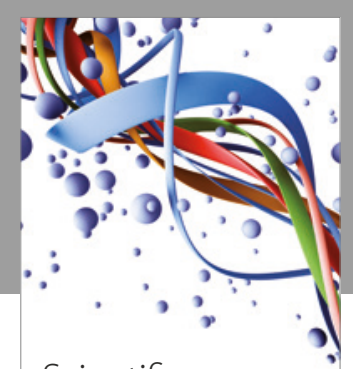

Scientifica
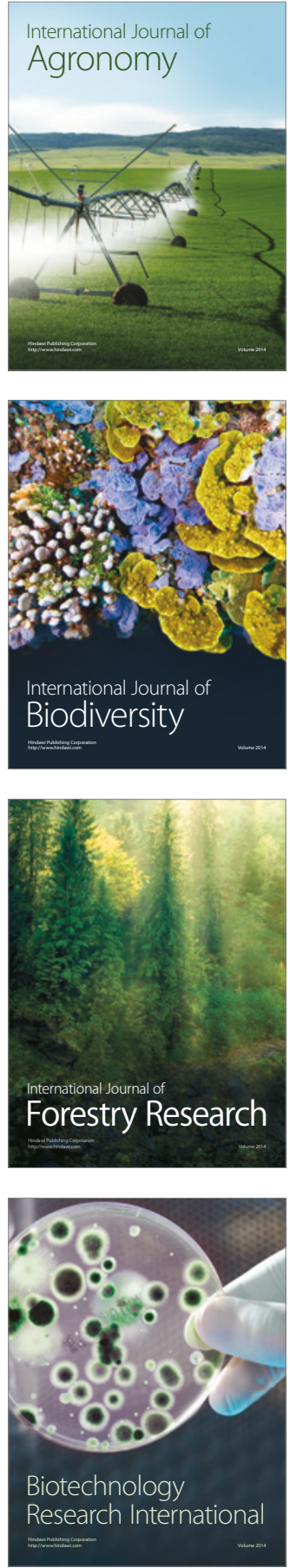
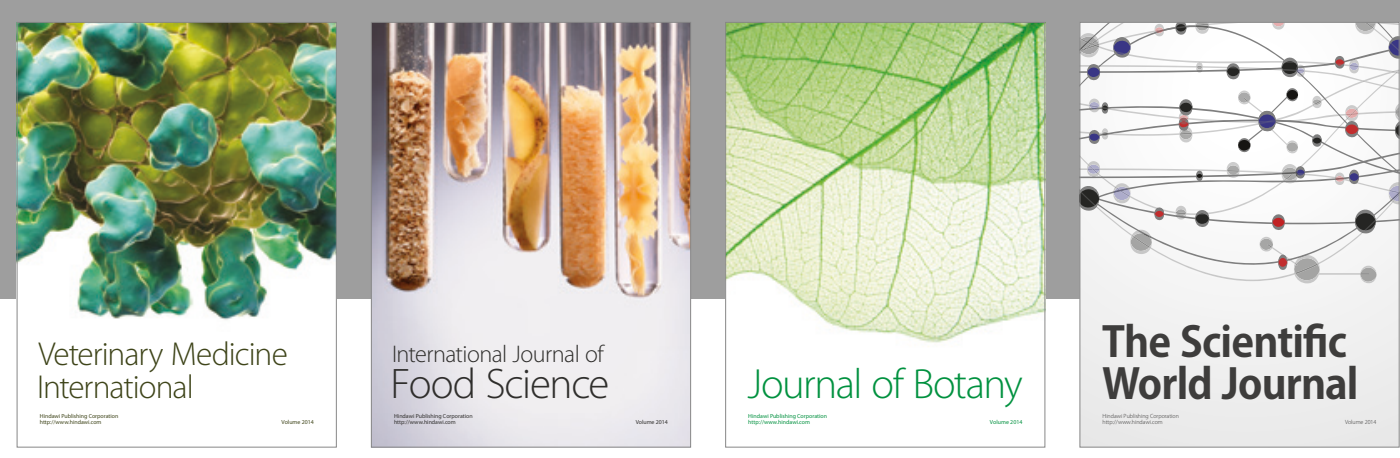

The Scientific

\section{World Journal}

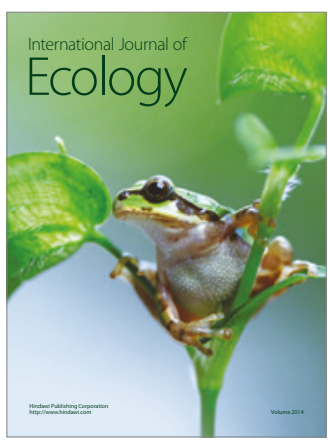

\section{Hindawi}

Submit your manuscripts at

https://www.hindawi.com
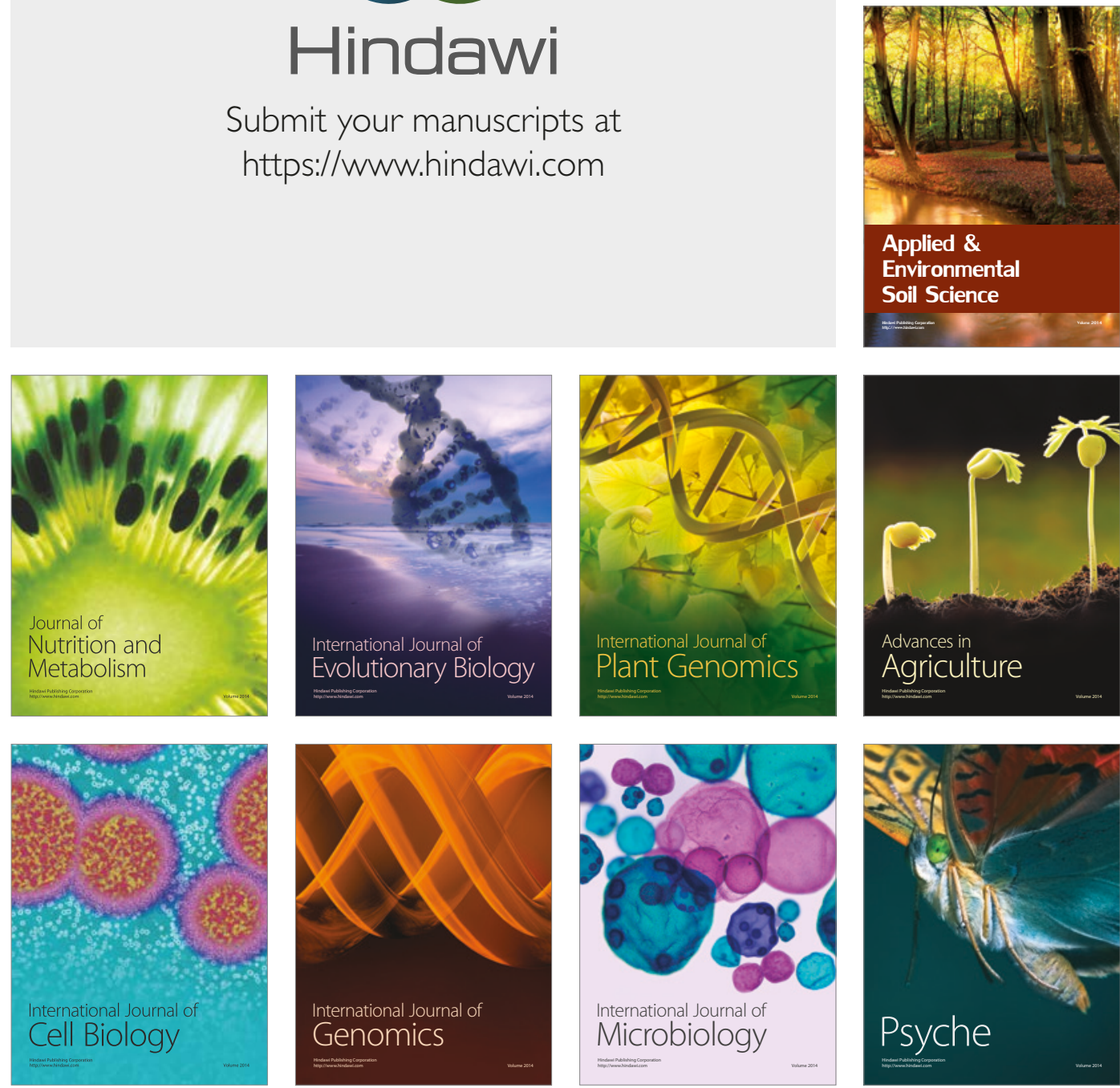

hternational Journal of Microbiology
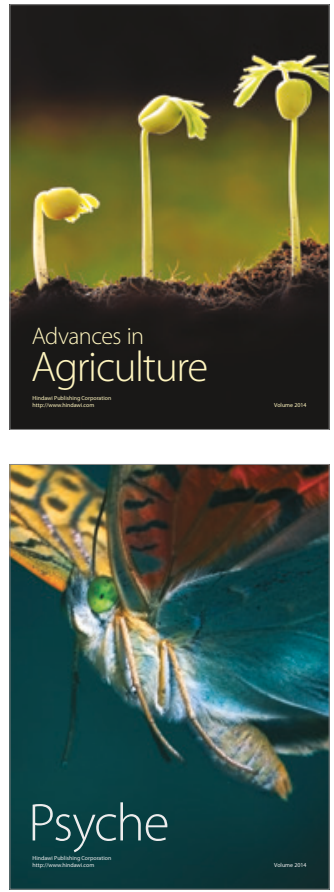